\title{
PENERAPAN MODEL LANCHESTER PADA PERTEMPURAN IWO JIMA
}

\author{
FEBRI DAUS, MAHDHIVAN SYAFWAN, BUDI RUDIANTO \\ Jurusan Matematika, \\ Fakultas Matematika dan Ilmu Pengetahuan Alam, Universitas Andalas, \\ Kampus UNAND Limau Manis Padang, Indonesia. \\ email : febridaus7@gmail.com
}

\begin{abstract}
Abstrak. Dalam makalah ini dibahas penurunan model Lanchester dan penerapannya pada pertempuran Iwo Jima. Model tersebut diselesaikan menggunakan metode variasi parameter, diaproksimasi menggunakan konsep jumlah Riemann dan kemudian dibandingkan dengan data empiris. Hasil-hasil yang diperoleh menunjukkan bahwa model Lanchester cukup akurat dalam memprediksi jumlah pasukan Amerika yang aktif bertempur di medan pertempuran tiap harinya.

Kata Kunci: Model Lanchester, metode variasi parameter, Jumlah Riemann, pertempur-
\end{abstract} an Iwo Jima

\section{Pendahuluan}

Para ilmuwan dan insinyur selalu terlibat dalam kegiatan militer sepanjang catatan sejarah. Salah satu contoh paling terkenal dalam sejarah kuno terjadi pada tahun 212 SM yakni tatkala kota Syracuse, Italia berhasil diselamatkan oleh Archimedes dari serangan armada laut Romawi dengan menciptakan sebuah mesin perang yang mampu menghancurkan kapal perang Romawi [6].

Dalam perkembangan selanjutnya, dunia militer juga tidak terlepas dari peranan matematika. Krisis politik dan keamanan global dan internasional seperti invasi Amerika dan beberapa negara Eropa ke negara lain, jaringan terorisme, bom bunuh diri dan sebagainya menjadi faktor pendorong dalam penerapan matematika di bidang militer.

Penerapan matematika yang menjadi bahasan dalam makalah ini terkait dengan model persamaan diferensial yang disebut persamaan Lanchester. Persamaan ini secara sederhana mendeskrispsikan hubungan kekuatan dua pasukan dalam sebuah pertempuran. Persamaan ini dimuat pertama kali dalam buku berjudul Aircraft Warfare: the Dawn of the Fourth Arm pada tahun 1916 karya Frederick Wiliam Lanchester (1868-1945), seorang insinyur Inggis.

Model Lanchester adalah model matematika pertama yang digunakan dalam memodelkan situasi pertempuran. Keakuratan dan verifikasi model Lanchester telah dilakukan oleh J.H. Engel dalam pertempuran Iwo Jima pada Perang Dunia II [5]. Makalah ini mengeksplorasi kembali kajian pada referensi [5]. 


\section{Model Lanchester}

Situasi pertempuran yang akan dibahas dalam makalah ini adalah pertempuran Iwo Jima yang terjadi pada 19 Februari - 26 Maret 1945 di pulau Iwo Jima, pintu gerbang menuju Tokyo. Selama pertempuran tidak ada pasukan Jepang yang ditarik ataupun ditambah. Di akhir pertempuran semua pasukan Jepang tewas. Selama beberapa hari pertama pertempuran, pasukan Amerika mendarat dengan jumlah pasukan yang bervariasi. Berkurangnya pasukan karena faktor operasional, seperti kecelakaan, cuaca buruk, dan lain-lain, dapat diabaikan.

Dalam keadaan seperti yang diceritakan di atas, persamaan Lanchester dapat dikembangkan menjadi [5]

$$
\begin{aligned}
& \frac{d X}{d t}=P(t)-a Y, a>0, \\
& \frac{d Y}{d t}=-b X, b>0,
\end{aligned}
$$

dengan

$t$ : Waktu (hari) sejak dimulai pertempuran,

$X(t)$ : Jumlah pasukan Amerika pada waktu $t$,

$Y(t)$ : Jumlah pasukan Jepang pada waktu $t$,

$a$ : tingkat berkurangnya pasukan Amerika,

$b$ : tingkat berkurangnya pasukan Jepang,

$P(t)$ : Jumlah pasukan Amerika yang disuplai ke medan pertempuran pada waktu $t$.

\section{Analisis Model}

Persamaan Lanchester untuk pertempuran Iwo Jima dapat ditulis dalam bentuk matriks sebagai berikut:

$$
\left(\begin{array}{l}
X^{\prime} \\
Y^{\prime}
\end{array}\right)=\left(\begin{array}{rr}
0 & -a \\
-b & 0
\end{array}\right)\left(\begin{array}{l}
X \\
Y
\end{array}\right)+\left(\begin{array}{c}
P(t) \\
0
\end{array}\right)
$$

Sistem (3.1) merupakan sistem persamaan diferensial linier nonhomogen dan dapat diselesaikan dengan metode variasi parameter.

(i) Untuk nilai eigen $\lambda_{1}=\sqrt{a b}$, diperoleh vektor eigen yang berkaitan dengan nilai eigen $\lambda_{1}=\sqrt{a b}$ adalah

$$
\left(\begin{array}{l}
V_{1} \\
V_{2}
\end{array}\right)=\left(\begin{array}{c}
1 \\
-\sqrt{b / a}
\end{array}\right)
$$

(ii) Untuk nilai eigen $\lambda_{2}=-\sqrt{a b}$, diperoleh vektor eigen yang berkaitan dengan nilai eigen $\lambda_{2}=-\sqrt{a b}$ adalah

$$
\left(\begin{array}{l}
U_{1} \\
U_{2}
\end{array}\right)=\left(\begin{array}{c}
1 \\
\sqrt{b / a}
\end{array}\right)
$$


Didapatkan matriks fundamental

$$
\Psi(t)=\left(\begin{array}{cc}
e^{\sqrt{a b} t} & e^{-\sqrt{a b} t} \\
-\sqrt{b / a} e^{\sqrt{a b} t} & e^{-\sqrt{a b} t} \sqrt{b / a}
\end{array}\right)
$$

Dengan menggunakan metode variasi parameter dimana

$$
\mathbf{x}_{0}=\left(\begin{array}{c}
X(0) \\
Y(0)
\end{array}\right) \text { dan } \mathbf{f}(t)=\left(\begin{array}{c}
P(t) \\
0
\end{array}\right)
$$

maka diperoleh

$$
\begin{aligned}
\left(\begin{array}{l}
X(t) \\
Y(t)
\end{array}\right)= & \Psi(t) \Psi(0)^{-1} \mathbf{x}_{0}+\Psi(t) \int_{0}^{t} \Psi(s)^{-1} \mathbf{f}(s) d s \\
= & \left(\begin{array}{c}
e^{\sqrt{a b} t} \\
-\sqrt{b / a} e^{\sqrt{a b} t} e^{-\sqrt{a b} t} \sqrt{b / a}
\end{array}\right)\left(\begin{array}{c}
1 \\
-\sqrt{b / a} \sqrt{b / a}
\end{array}\right)^{-1}\left(\begin{array}{c}
X(0) \\
Y(0)
\end{array}\right), \\
& +\left(\begin{array}{cc}
e^{\sqrt{a b} t} & e^{-\sqrt{a b} t} \\
-\sqrt{b / a} e^{\sqrt{a b} t} e^{-\sqrt{a b} t} \sqrt{b / a}
\end{array}\right) \int_{0}^{t}\left(\begin{array}{cc}
e^{\sqrt{a b} s} & e^{-\sqrt{a b} s} \\
-\sqrt{b / a} e^{\sqrt{a b} s} & e^{-\sqrt{a b} s} \sqrt{b / a}
\end{array}\right)\left(\begin{array}{c}
P(s) \\
0
\end{array}\right) d s \\
= & \left(\begin{array}{c}
X(0) \cosh \sqrt{a b}-\sqrt{a / b} Y(0) \sinh \sqrt{a b} t+\int_{0}^{t} \cosh \sqrt{a b}(t-s) P(s) d s \\
Y(0) \cosh \sqrt{a b} t-\sqrt{b / a} X(0) \sinh \sqrt{a b} t-\int_{0}^{t} \sinh \sqrt{a b}(t-s) P(s) d s
\end{array}\right) .
\end{aligned}
$$

Dengan demikian diperoleh solusi umum

$$
\begin{aligned}
& X(t)=X(0) \cosh \sqrt{a b}-\sqrt{a / b} Y(0) \sinh \sqrt{a b} t+\int_{0}^{t} \cosh \sqrt{a b}(t-s) P(s) d s,(3 . \\
& Y(t)=Y(0) \cosh \sqrt{a b} t-\sqrt{b / a} X(0) \sinh \sqrt{a b} t-\int_{0}^{t} \sinh \sqrt{a b}(t-s) P(s) d s(3 .
\end{aligned}
$$

Persamaan (3.2) - (3.3) dapat diimplementasikan pada situasi dimana nilai $a$ dan $b$ dapat ditentukan sedemikian sehingga data riil sesuai dengan nilai yang diperoleh dari persamaan $(3.2)$ - (3.3).

Dari data pertempuran Iwo Jima dapat dihitung nilai $X_{t}^{*}$, yaitu jumlah pasukan Amerika pada hari ke- $t$. Selain itu dari data juga dapat dihitung nilai $p^{*}(t, t+1)$, yaitu jumlah pasukan Amerika yang disuplai ke medan pertempuran dari waktu $t$ sampai $t+1$. Untuk mengkarakterisasi fungsi $P(t)$ pada semua nilai $t$ sehingga persamaan (3.2)-(3.3) dapat digunakan, maka perlu diberikan asumsi bahwa tingkat suplai pasukan Amerika yang dikerahkan ke medan pertempuran bernilai konstan pada hari-hari pertempuran, yaitu

$$
P(s)=p^{*}(t, t+1), \text { untuk } t \leq s<t+1, t \text { bilangan bulat tak-negatif. }
$$


Dengan asumsi ini dan mengganti nilai $X(0)$ dan $Y(0)$ berturut-turut dengan $X_{0}^{*}$ dan $Y_{0}^{*}$, persamaan (3.2) - (3.3) dapat ditulis ulang menjadi

$$
\begin{aligned}
X(0)= & X_{0}^{*}=0 \\
X(t+1)= & -\sqrt{a / b} Y(0) \sinh \sqrt{a b}(t+1)+\int_{0}^{t+1} \cosh \sqrt{a b}(t-s+1) P(s) d s \\
= & -\sqrt{a / b} Y(0)(\sinh \sqrt{a b} t \cosh \sqrt{a b}+\sinh \sqrt{a b} \cosh \sqrt{a b} t) \\
& +\int_{0}^{t}(\cosh \sqrt{a b}(t-s) \cosh \sqrt{a b}+\sinh \sqrt{a b}(t-s) \sinh \sqrt{a b}) P(s) d s \\
& +\int_{t}^{t+1}(\cosh \sqrt{a b}(t-s) \cosh \sqrt{a b}+\sinh \sqrt{a b}(t-s) \sinh \sqrt{a b}) P(s) d s .
\end{aligned}
$$

Karena $P(s)=p^{*}(t, t+1)$ maka

$$
\begin{aligned}
X(t+1)= & -\sqrt{a / b} Y(0) \sinh \sqrt{a b} t \cosh \sqrt{a b}+\int_{0}^{t} \cosh \sqrt{a b}(t-s) \cosh \sqrt{a b} \\
& -\left(\sqrt{a / b} Y(0) \sinh \sqrt{a b} \cosh \sqrt{a b} t-\int_{0}^{t} \sinh \sqrt{a b}(t-s) \sinh \sqrt{a b} P(s) d s\right) \\
& +\int_{t}^{t+1}(\cosh \sqrt{a b}(t-s) \cosh \sqrt{a b}+\sinh \sqrt{a b}(t-s) \sinh \sqrt{a b}) p^{*}(t, t+1) d s \\
= & X(t) \cosh \sqrt{a b}-\left(Y(t)-\frac{p^{*}(t, t+1)}{a}\right) \sqrt{a / b} \sinh \sqrt{a b}, \\
Y(0)= & Y_{0}^{*} \\
Y(t+1)= & Y(0) \cosh \sqrt{a b}(t+1)-\sqrt{b / a} \int_{0}^{t+1} \sinh \sqrt{a b}(t-s+1) P(s) d s
\end{aligned}
$$

Karena $P(s)=p^{*}(t, t+1)$ maka

$Y(t+1)=Y(0)(\cosh \sqrt{a b} t \cosh \sqrt{a b}+\sqrt{b / a} \sinh \sqrt{a b} t \sinh \sqrt{a b})$

$$
\begin{aligned}
& -\left(\sqrt{b / a} \int_{0}^{t}(\sinh \sqrt{a b}(t-s) \cosh \sqrt{a b}+\cosh \sqrt{a b}(t-s) \sinh \sqrt{a b}) P(s) d s\right) \\
& \left.+\int_{t}^{t+1}(\sinh \sqrt{a b}(t-s) \cosh \sqrt{a b}+\cosh \sqrt{a b}(t-s) \sinh \sqrt{a b}) p^{*}(t, t+1) d s\right) \\
= & \left(Y(t)-p^{*}(t, t+1) / a\right) \cosh \sqrt{a b}-X(t) \sqrt{b / a} \sinh \sqrt{a b}+p^{*}(t, t+1) / a .
\end{aligned}
$$

Dengan demikian diperoleh

$$
\begin{aligned}
X(0)= & \\
X(t+1)= & X(t) \cosh \sqrt{a b} \\
& -\left(Y(t)-\frac{p^{*}(t, t+1)}{a}\right) \sqrt{a / b} \sinh \sqrt{a b}, \\
Y(0)= & Y_{0}^{*} \\
Y(t+1)= & \left.\left(Y(t)-\left(p^{*}(t, t+1) / a\right)\right) \cosh \right) \sqrt{a b} \\
& -\left(X(t) \sqrt{b / a} \sinh \sqrt{a b}+p^{*}(t, t+1) / a .\right.
\end{aligned}
$$


Jika nilai $a$ dan $b$ dapat ditentukan sedemikian sehingga nilai $X(t)$ cocok dengan nilai $X^{*}(t)$ (dari data riil) dan dengan menggunakan $Y(0)=Y_{0}^{*}$ dan $Y(T)=Y_{T}^{*}$, dimana $T$ menyatakan waktu berakhir pertempuran, maka dapat disimpulkan bahwa persamaan (3.4)-(3.5) dapat mendeskripsikan pertempuran dengan baik. Berikut akan dijelaskan cara mengaproksimasi nilai $a$ dan $b$.

Pertama akan ditentukan aproksimasi nilai $b$. Dengan mengintegralkan persamaan (2.2) dari 0 ke $T$, diperoleh

$$
\int_{0}^{T} d Y=\int_{0}^{T}(-b X) d t
$$

Subtitusikan $X(0)=0, X(t) \approx X_{t}^{*}$ untuk $0<t<T, Y(0)=Y_{0}^{*}, Y(t)=Y_{T}^{*}$, maka persamaan (3.6) menjadi

$$
\left(Y_{T}^{*}-Y_{0}^{*}\right) \approx-b \int_{0}^{T} X_{t}^{*} d t
$$

Dengan menggunakan konsep jumlah Riemann dimana $\Delta t=t+1-t=1$, maka integral pada persamaan (3.6) dapat diaproksimasi dengan $\int_{0}^{t} X_{t}^{*} d s \approx \sum X_{s}^{*}$, sehingga persamaan (3.7) menjadi

$$
\begin{aligned}
\left(Y_{T}^{*}-Y_{0}^{*}\right) & \approx-b \Sigma_{i=1}^{T} X_{t}^{*} \\
b & \approx\left(Y_{0}^{*}-Y_{T}^{*}\right) / \Sigma_{t=1}^{T} X_{t}^{*} .
\end{aligned}
$$

Selanjutnya untuk mengaproksimasi nilai $Y(t)$ di setiap $t(0<t<T)$, integralkan persamaan (2.2) dari 0 ke $t$ sehingga diperoleh

$$
\int_{0}^{t} d Y=-b \int_{0}^{t} X d s \Longleftrightarrow Y(t)=Y(0)-b \int_{0}^{t} X d s .
$$

Gunakan aproksimasi jumlah Riemann $\int_{0}^{t} X d s \approx \sum_{s=1}^{t} X_{s}^{*}$, maka persamaan (3.9) menjadi

$$
Y(t) \approx Y(0)-b \sum_{s=1}^{t} X_{s}^{*}
$$

Misalkan ruas kanan persamaan (3.10) dinyatakan dengan $\tilde{Y}(t)$, maka nilai $Y(t)$ diaproksimasi oleh

$$
\tilde{Y}(t)=Y(0)-b \sum_{s=1}^{t} X_{s}^{*}
$$

Karena diketahui $\tilde{Y}(0)=Y_{0}^{*}$, maka diperoleh

$$
\begin{aligned}
& \tilde{Y}(0)=Y_{0}^{*}, \\
& Y(t) \approx Y_{0}^{*}-b \sum_{s=1}^{t} X_{s}^{*}, t>0 .
\end{aligned}
$$

Nilai $\tilde{Y}(t)$ pada persamaan (3.11) disebut aproksimasi nilai teoritis dari $Y(t)$ karena nilai tersebut diperoleh dari data dan persamaan (2.2). 
Dengan menggunakan nilai $\tilde{Y}(t)$ kemudian mengintegralkannya dari 0 sampai $S$, dimana $S$ adalah waktu tetap sebelum berhentinya pertempuran dan menggunakan $M(S) \approx \tilde{M}_{S}^{*}$, maka diperoleh

$$
\begin{aligned}
\int_{0}^{S} d X & =\int_{0}^{S}(P(t)-a Y) d t \\
X_{S}^{*} & \approx \int_{0}^{S} P(t)-a \int_{0}^{S} \tilde{Y} d t .
\end{aligned}
$$

Dengan menggunakan konsep jumlah Riemann seperti sebelumnya, maka nilai $a$ dapat diaproksimasi sebagai berikut:

$$
a \approx\left(\sum_{t=0}^{s} P(t)-X_{s}^{*}\right) / \sum_{t=0}^{s} \tilde{Y}(t)
$$

Dengan melakukan cara yang serupa pada langkah sebelumnya, diperoleh

$$
\tilde{X}(t)=\Sigma_{t=0}^{S} P(t)-a \Sigma_{t=0}^{S} \tilde{Y}(t) .
$$

\subsection{Penerapan Model Lanchester pada Pertempuran Iwo Jima}

Pertempuran Iwo Jima melibatkan 54.000 pasukan Amerika di hari pertama, 0 pasukan di hari kedua, 6.000 pasukan di hari ketiga, 0 pasukan di hari ke empat dan lima, 13.000 pasukan di hari ke enam, dan 0 pasukan di hari setelah itu.

$$
P(s)=\left\{\begin{aligned}
54000, & 0 \leq s<1 \\
0, & \leq s<2 \\
6000, & \leq s<3 \\
0, & \leq s<4 \\
0, & \leq s<5 \\
13000, & \leq s<6 \\
0, & \text { selainnya }
\end{aligned}\right.
$$

Dari data yang tersedia tentang pertempuran Iwo Jima [5], diperoleh fakta bahwa pertempuran berakhir pada saat $T=36$ dengan $\Sigma X_{t}^{*}=2.037 .000, Y_{0}^{*}=$ 21.500, dan $Y_{T}^{*}=0$. Dengan menggunakan nilai-nilai tersebut didapatkan aproksimasi nilai $b$ dari persamaan (3.8), yaitu $b \approx 0.0106$.

Selanjutnya nilai $S$ yang digunakan untuk menghitung aproksimasi nilai $a$ adalah 28. Hal ini karena pulau dideklarasikan aman pada hari ke-28, meskipun pertempuran masih berlangsung hingga hari ke-36. Untuk $S=28$, diperoleh dari data [5] bahwa $X_{s}^{*}=52.735, \sum_{0}^{S} P(t)=73.000$, dan $\tilde{Y}(t)=372.500$, sehingga didapatkan aproksimasi nilai $a$ dari persamaan (3.12), yaitu $a \approx 0.0544$.

Aproksimasi nilai $a$ dan $b$ yang diperoleh tersebut digunakan untuk menghitung solusi $X(t)$ dan $Y(t)$ pada persamaan (3.4) dan (3.5). Nilai-nilai $X(t)$ dan $Y(t)$ untuk setiap $t=0,1,2, \cdots, 36$ ditampilkan pada grafik jumlah pasukan Amerika yang aktif bertempur dari hari ke hari.

Jika dibandingkan hasil teoritis (Gambar 1) dengan data riil (garis titik-titik bagian bawah Gambar 2), maka dapat disimpulkan bahwa model Lanchester (2.1)(2.2) cukup akurat memprediksi jumlah riil pasukan Amerika Serikat yang aktif bertempur dari hari ke hari dalam pertempuran Iwo Jima. 


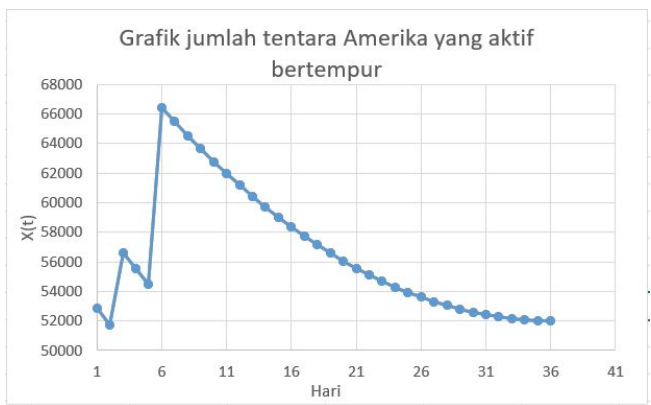

Gambar 1. Grafik jumlah pasukan Amerika yang aktif bertempur di medan pertempuran setiap hari yang diperoleh dari persamaan (3.4) dan (3.5)

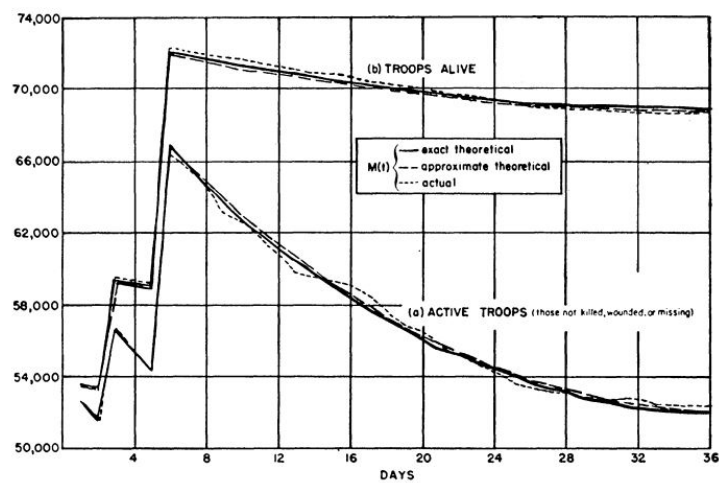

Fig. 1: $M(t)$, number of United States troops in action.

Gambar 2. Grafik data riil (garis titik-titik) pasukan Amerika yang aktif bertempur dalam perang Iwo Jima

\section{PENUTUP}

\subsection{Kesimpulan}

Pada makalah ini telah dibahas penurunan model Lanchester pada pertempuran Iwo Jima. Dari hasil yang diperoleh dapat disimpulkan bahwa model Lanchester cukup akurat dalam memprediksi jumlah pasukan Amerika yang aktif bertempur di medan perang tiap harinya.

\subsection{Saran}

Model Lanchester dapat juga dikembangkan untuk berbagai pertempuran di dunia yang memiliki data empiris, sehingga dapat dikembangkan untuk perkembangan dunia militer. 


\section{Ucapan Terima kasih}

Penulis mengucapkan terima kasih kepada Bapak Efendi, Bapak Ahmad Iqbal Baqi dan Bapak Effendi yang telah memberikan masukan dan saran sehingga paper ini dapat diselesaikan dengan baik.

\section{Daftar Pustaka}

[1] Susanto, Hadi. 2015. Tuhan Juga Ahli Matematika. Yogyakarta: Bentang Pustaka.

[2] Gardono, Frank R. Fox, William P. Horten, Steven B. 2014. A First Course in Mathematical Modeling. Boston : Premedia Global.

[3] Boyce, W. E dan Prime. 2001. Elementary Differential Equations and Boundary Value Problems. New York: John Wiley Sons.

[4] Varberg, Purcell, Rigdon. 2004. Kalkulus Edisi 8. Jakarta: Erlangga.

[5] Engel, J. H. 1994: A Verification of Lanchester's Law. Journal of the Operation Research Society of America. Vol.2, No.2: 103 - 171.

[6] Ojong, P.K. 2006. Perang Pasifik. Jakarta: Buku Kompas.

[7] Wright, Derrick. 2001. The Marines Raise the Flag on Mount Suribachi. Oxford : Osprey Publishing.

[8] Wazwaz, A. M. 2009. Partial Differential Equation and Solitary Waves Theory. Berlin: Springer. 